\title{
A COVID-19 e as empresas solidárias: uma nova face do empresariado brasileiro?
}

Eva Aparecida Rezende de Moraes ${ }^{1}$

A COVID-19 esteve aqui, em 2020, e, pelo jeito, vai ficar nos tirando o sono até, no mínimo, se descobrir uma vacina, um remédio, algo eficaz contra esse "inimigo invisível". Uma verdadeira "guerra" se instalou: não entre países, mas no mundo inteiro! Também não escolheu "rostos", todos fomos afetados: todos os "mundos" (primeiro, segundo e terceiro), os pobres e os ricos, os jovens e os velhos, os que possuem comorbidades e os saudáveis, os do centro e os da periferia, os que têm plano de saúde e os que têm somente o SUS,... Entretanto, de todos os afetados, os mais vulneráveis sofreram mais!

\section{Os pobres? São os pobres!}

Se a coronavirus não escolhe "rostos", é certo que a pandemia impacta de forma desigual os ricos e os pobres (SAKAMOTO, 2020: https://noticias.uol.com.br/colunas/leonardosakamoto/2020/03/15/coronavirus-nao-prefere-pobre-ou-rico-masgovernos-e-suas-politicas-sim.htm)! A julgar pelas análises, um pequeno grupo de "capitalistas selvagens", de lideranças religiosas e de líderes políticos parece não ter percebido isto: quem pôde, ficou de quarentena, em casa, mas os mais pobres - os que moram nas ruas, os que estão Comunidades de periferias e em bairros sem infraestrutura - não puderam se resguardar. Os pobres tiveram que trabalhar: "autônomos" (nome chique para quem faz "bico", vendedores ambulantes, "guardadores" de carros, os que "se viram" para sobreviver), domésticas, faxineiras, cuidadoras de idosos, mecânicos, maquinistas, porteiros, garis, empregados de "serviços gerais" e de "serviços essenciais" (supermercados, hortifrutis, padarias, alguns tipos de indústrias), agricultores, caminhoneiros, motoristas de diversas categorias, motoboys, entregadores, coveiros

\footnotetext{
${ }^{1}$ Doutora em Teologia pela PUC-Rio e professora do Departamento de Teologia da PUC-Rio (Setor de Cultura Religiosa).
} 
e outros profissionais (sem enumerar os bombeiros, os profissionais da saúde e os policiais, que, se não são pobres, também não são ricos!) não puderam ficar em casa! Muita gente!

Além disso, os pobres não possuem, com regularidade, água encanada e tratada e-ou rede de esgoto... Os pobres moram em locais superlotados - "casas" minúsculas, quitinetes, barracos e outras "residências" que abrigam até uma dezena de pessoas! Os pobres se amontoaram: nas portas das agências da Caixa Econômica Federal, em busca de míseros $\mathrm{R} \$ 600$ para comprar comida; na porta de hospitais, UPAs, emergências, em busca de atendimento; nas portas de lideranças religiosas em busca de cesta básica, pão e produtos de higiene e limpeza; nas portas de funerárias, que já não davam mais conta de tantos caixões deveriam disponibilizar,... Enfim, os pobres não se resguardaram: se submeteram. Além disso, os de classe mais elevada tiveram condições de fazerem testes mais rápidos, acessaram primeiro os hospitais particulares de ponta (foram os mais ricos que se infectaram fora do Brasil e trouxeram o vírus para cá), enfim, tiveram mais condições de se proteger. Não é o caso, aqui, de "vitimizar" os pobres e "culpabilizar" os ricos, não é isso! Nem é, este ensaio, uma palavra ideológica ou politicamente partidária - é uma simples, lógica e matemática constatação: os de classe econômica mais abastada tiveram mais condições de reagirem e se resguardarem do que os pobres. Ponto.

\section{2. (Re)Aprendendo a se adaptar em época de crise}

Mas a covid-19 está deixando lições! Você, leitor, deve ter aprendido algumas delas - ou, ao menos, escutado falar sobre. São lições desde aprender a ficar sozinho e a lidar com a solidão; a refletir sobre a morte e a finitude da existência; a sentir a perda de quem amamos e a nos alegrar pela recuperação de quem amamos; a conviver e a (re)aprender a fazer coisas juntos; a cuidar da higiene pessoal e a cuidar da higiene da casa; a rezar e a meditar; teve até quem pintou a casa, descobriu novas habilidades, deu show musical para os vizinhos na varanda de sua casa, se dedicou mais aos estudos, descobriu habilidades nunca antes imaginadas,... 
Mas houve, também, muita gente que olhou para o lado (ou para baixo) e descobriu outro ser humano que necessitava de sua ajuda! Descobriu que o pouco que podia fazer era muito para outros que não tinham nada! Em todas as diversas situações éticas que a COVID-19 nos proporcionou, o que mais me chamou a atenção (desculpe usar o pronome na primeira pessoa) foram os gestos de solidariedade e empatia que brotaram, aqui e acolá. E, dentre esses gestos, achei importante um em especial: a atitude de algumas empresas privadas, em solidariedade às pessoas mais vulneráveis à pandemia de nossa sociedade. Por quê? Simples: espera-se atitude solidária de ONGs, entidades filantrópicas, organizações religiosas, governos, mas não de empresários! Imaginei empresários cuidando de suas vidas privadas, enquanto seus funcionários continuariam amealhando riquezas para suas contas bancárias! E fui assistindo meio desconfiada no início, confesso - alguns empresários se unirem, superando antagonismos e concorrências, para salvar vidas, que, nem sempre, eram as de seus clientes! Empresários de áreas não afins fazendo respiradores e, outros, produzindo EPIs (equipamentos de proteção individuais); empresários que se juntaram a entidades filantrópicas e distribuíram alimentos em comunidades carentes; empresários que contrataram presidiários e pessoas de comunidades pobres para fazer máscaras; empresários do ramo de chocolate que, na Páscoa, distribuíram ovos a crianças em hospital de câncer;... e por aí vai!

Meu objetivo principal, aqui, portanto, é mostrar aos jovens, que estão ingressando na vida profissional, a possibilidade de construir relações mais humanas entre empresas privadas e sociedade. Resolvi partilhar algumas dessas percepções com você, querido leitor, e tentar mostrar que - sim! - isto é possível: mostrar um "rosto mais humano" das empresas e que, atrás de uma cadeira de presidência, existe "gente" e, não, robô; mostrar que é possível ter lucro, ganhar dinheiro, e nem por isso ser movido por ganância! Sonho? Ingenuidade? Ou um olhar mais acurado, que percebe um leve sinal de mudança possível nas relações entre empresas privadas e sociedade? Não me preocupo em responder: este pequeno ensaio (não o classifico como um "artigo") busca ser, apenas, um pequeno aporte - com base jornalística e cristológica - 
para alimentar uma possibilidade real. Partilharei algumas manchetes de sites e buscarei tirar lições ético-teológicas dessa experiência.

\section{Empresas privadas se movimentam!}

As marcas das empresas que foram solidárias aos mais vulneráveis da sociedade durante a pandemia não foram divulgadas no início, mas muitos acharam - e eu também - que elas deveriam aparecer: assim também pensou a seção "Solidariedade S.A", do Jornal Nacional da Rede Globo (in: https://g1.globo.com/jornalnacional/noticia/2020/04/14/solidariedade-sa-conheca-acoes-

solidarias-de-empresas-e-empresarios-durante-a-pandemia.ghtml). Por que não? Deram um belo exemplo, em detrimento, infelizmente, de outros empresários, que ainda só enxergam benesses para si ou para seu empreendimento. Diante dos bons exemplos de solidariedade, resolvi destacar isto. Comecemos pelos bancos privados.

O Itaú/Unibanco doou $\mathrm{R} \$ 1$ bilhão para ajudar o enfrentamento da pandemia; sua campanha: "Todos pela Saúde", foi administrada por especialistas (todos voluntários). Sua ação foi em função de quatro pilares: (i) informar (esclarecimento à população), (ii) proteger (compra de testes equipamentos de proteção), (III) cuidar (construção de hospitais de campanha); (iv) retomar (preparar a sociedade para o "pós" pandemia). Suas ações, até a última semana de abril, foram: apoio à Fundação Oswaldo Cruz para a construção de um hospital em Manguinhos; aquisição de 190 respiradores para ambulâncias e hospitais; distribuição de equipamentos para hospitais de campanha em Pacaembu e Anhembi; aumento de 10 leitos do Hospital Municipal Moyses Deutsch; impressão em 3D, de 2.000 ventiladores mecânicos; infraestruturas da tenda de campanha do Hospital do Grajaú; cestas de alimentos para o Movimento dos Trabalhadores Sem Teto (centro de São Paulo); cestas básicas e kits de higiene para 2.000 famílias de Paraisópolis; cestas básicas e kits de higiene para 3.000 famílias de Heliópolis; apoio a famílias de Paraisópolis, através do Instituto Pró-saber, apoio às famílias: da região de M'Boi Mirim (em Jardim Ângela e Jardim São Luís), do Município São Vicente (São Paulo) e do Complexo da Maré (https://www.itau.com.br/coronavirus/; 
https://www.itau.com.br/coronavirus/doacoes/). Além destas iniciativas, o Itaú/Unibanco se uniu ao Banco Bradesco e ao Banco Santander em um investimento de $\mathrm{R} \$ 282$ milhões na importação de equipamentos médicos, testes rápidos para detecção da covid-19 e confecção de máscaras (in: G1, op. Cit.).

E, por falar em Santander, este banco se comprometeu a não demitir funcionários em todo o território nacional por motivo de covid19, antecipou o $13^{\circ}$ salário dos 47 mil funcionários para o mês de abril, disponibilizou uma linha de crédito para que empresas clientes do banco não demitissem funcionários, reforçou ações de higienização e limpeza, ampliou o sistema "home office", promoveu doações a instituições que atuam na linha de frente de combate ao corona vírus, acrescentou o dobro do valor doado pelos seus clientes para a pandemia (https://br.superamosjuntos.com/vida-em-casa/).

O Bradesco, diante da pandemia, antecipou a primeira parcela do $13^{0}$ salário de seus funcionários para abril; suas agências funcionaram durante a pandemia em sistema de rodízio (para poupar seus funcionários do contágio); grande parte de seus funcionários (grupo de risco, estagiários e menores) ficaram em home office (https://exame.abril.com.br/negocios/bradesco-antecipa-1a-parcelado-13o-salario-a-funcionarios-por-coronavirus/). Além disso, importou 500 monitores de UTI da China, que foram doados (in G1, op. Cit.).

O Banco BV, em seu site, alegou que "a solidariedade é o nosso principal papel como sociedade" e, sob a bandeira da "Corrente do Bem", doou R\$ 30 milhões para ajudar na infraestrutura hospitalar e famílias vulneráveis. Lançou, também, uma campanha de doações denominada \#LeveASerio, garantindo transparência e rapidez na aplicação dos recursos, sendo apoiado pelo Instituto Votorantim e pela Fundação Banco do Brasil: a cada $\mathrm{R} \$ 1,00$ doado por uma pessoa, o banco doaria, igualmente, $R \$ 1,00$ - a meta era alcançar $\mathrm{R} \$ 10$ milhões. Ele agiu juntamente com outros parceiros: Instituto Esporte e Educação (atenderam 859 famílias na região de Heliópolis), Instituto Serginho 10 (atenderam 93 famílias em Guarulhos), Instituto Proeza (doação de 500 cestas básicas ao Instituto, em Brasília), Projeto Viver (atenderam 210 famílias no Complexo de Paraisópolis), Rede D’Or (construção de um Hospital de Campanha, no Rio de Janeiro), M4 nas Escolas (doação de cartão alimentação para 95 famílias na região da Penha e do 
Andaraí), Projeto Reação (atendimento a 1.400 famílias de Comunidades carentes da cidade do Rio de Janeiro), Instituto Próxima Geração (cartão alimentação a 98 famílias na região do Parque dos Príncipes). Além disso, o BV doou $R \$ 3,5$ milhões para a compra de respiradores para hospitais da rede pública de São Paulo (https://bancobv.abraceumacausa.com.br/?utm_source=adwords\&ut m_medium=texto\&utm_content=abraceummacausa_texto_ajuda_a wareness_adwaw002\&utm_campaign=brand_db_awareness\&utm_term =20020202\&gclid=EAlalQobChMI5N779L CG6QIVjgyRCh0bOAesEAAYASAAEglk9vD_BwE).

Uma rede de saúde privada se destacou: a Rede D'Or de Hospitais, que aplicou $R \$ 120$ milhões, em parceria com várias empresas no Rio de Janeiro (Bradesco Saúde, Lojas Americanas, Banco Safra, P\&G, Fundo Mubdala, Vale, Sul América, BV, Stone e Instituto Brasileiro de Petróleo, Gás e Biocombustível): ajudou a construir dois hospitais de campanha e abriu 108 novos leitos no Hospital São Francisco da Ordem Terceira Penitência (em parceria com a United Health Care), Em São Paulo, reformou a Santa Casa de Misericórdia (em parceria com a Sul América e a Qualicorp) e comprou respiradores pulmonares e insumos médicos (in G1, op. Cit., e https://www.sunoresearch.com.br/noticias/coronavirus-rede-dor-doa-110-mi-hospitais-publicos/).

Outra iniciativa envolvendo a Rede D'Or foi a "Dados do Bem", liderada pelo Instituto D'Or de Pesquisa e Ensino (IDOR), em parceria com Zoox Smart Data: fizeram e distribuíram um aplicativo gratuito, que identificava a concentração de transmissão da covid-19 e a análise da evolução da imunidade na população. Quem respondia ao questionário e apresentava alta probabilidade de infecção, era convidado a fazer um teste gratuito, com dia e horário marcados, e, se fosse confirmado o contágio, poderia indicar até cinco pessoas com as quais ele teve contato, que eram, também, convidadas a fazer o teste. Este projeto Dados do Bem se iniciou no dia 28 de abril de 2020, no Rio de Janeiro; a Secretaria de Estado de Saúde do Rio de Janeiro utilizou a tecnologia do Dados do Bem para a aplicação de testes. O Shopping Via Parque, na Barra da Tijuca, também entrou na parceria e cedeu espaço no estacionamento para a instalação da tenda Dados do Bem 
(https://www.rededorsaoluiz.com.br/hospital/udi/novidades/dados-dobem-idor-e-zoox-mapearao-a-covid-19) .

Em 31 de março de 2020, três empresários de Curitiba que têm impressoras 3D (um era Felipe Aranega, da empresa Produteca) formaram um pequeno grupo em uma rede social e se propuseram a fabricar máscaras-escudo para combater a covid-19 - visto que a empresa tcheca disponibilizou o código para quem quisesse produzir. No dia 28 de abril, se consolidava a Atitude $3 D$ (https://www.instagram.com/atitude3dvoluntario/), integrando 150 pessoas, 25 produtores ativos, uma cadeia de fornecedores e os servidores públicos estaduais; arrecadaram, à época, mais de $R$ \$ 10 mil, entregaram 2,2 mil máscaras em apenas uma semana e já tinham 10,3 mil novas encomendas! Tudo começou com uma conversa informal entre amigos com um desejo único de ajudar; em pouco tempo, reuniram engenheiros, médicos e idealizadores; em seguida, Henrique Domakoski (superintendente de Inovação da Casa Civil do Paraná) ofereceu os veículos para fazer a distribuição das máscaras! Uma união perfeita entre partilha, criatividade, tecnologia e inovação (desde a doação do código para impressão das máscaras feita pela empresa tcheca, passando pela "vaquinha" no site, até os voluntários para fabricar e distribuir)! (http://www.aen.pr.gov.br/modules/noticias/article.php?storyid=10637 2\&tit=Paranaenses-produzem-mascaras-escudo-e-Governo-faz-adistribuicao)

E a lista de empresas poderia ser mais extensa - como a Ambev e a Boticário, que adaptaram suas fábricas para produzirem álcool em gel (https://www.istoedinheiro.com.br/a-economia-dasolidariedade/). A AMBEV produziu 500 mil garrafas de álcool que foram entregues às Secretarias de Saúde de São Paulo, Rio de Janeiro e Brasília; o fundador e presidente do Conselho de Administração do grupo Boticário - Miguel Krigsner - afirmou: Nossa essência é ser agente de transformação em tudo o que fazemos. Se salvarmos uma vida, salvamos a humanidade (ibidem) - ao doar 1,7 tonelada de álcool gel para a Secretaria Municipal de Saúde de Curitiba. Outro exemplo: a construtora MRV, o Banco Inter e a Log $\mathrm{CP}$ destinaram $\mathrm{R} \$ 10$ milhões para o Governo de Minas Gerais adquirir novos respiradores artificiais; a distribuidora de energia EDP, em São Paulo, disponibilizou $R \$ 6$ milhões para a aquisição de 
respiradores para UTIs de hospitais públicos neste Estado; e, junto com ela, umas 150 empresas levantaram, em poucos dias, $R \$ 23,4$ milhões para a compra de aparelhos essenciais para a rede pública de saúde... Enfim, a lista é grande, e somente no Brasil - imagino isto se repetindo pelo mundo afora! Isto tem que nos dizer alguma coisa!

\section{Solidariedade? Empatia? Ou Responsabilidade Social?}

Todos sabemos os significados de solidariedade, empatia, responsabilidade social; mas é sempre bom "revisitar" esses significados:

Solidariedade. Qualidade de quem está disposto a ajudar, acompanhar ou defender outra pessoa, numa dada circunstância. Compadecimento com as dificuldades ou sofrimentos de outras pessoas (...). Identificação com as misérias alheias; conhecimento do sofrimento daqueles que são pobres. Partilha de interesses e opiniões (...). Manifestação desse sentimento com o propósito de ajudar; ajuda, amparo, apoio. (...) Identificação de pensamentos, ideias, sensações, sentimentos, etc. (https://www.dicio.com.br/solidariedade/)

Empatia. Capacidade psicológica para sentir o que sentiria uma outra pessoa, caso estivesse na mesma situação vivenciada por ela; (...) tentar compreender sentimentos e emoções, procurando experimentar de forma objetiva e racional o que sente outro indivíduo. (...) Está intimamente ligada ao altruísmo - amor e interesse pelo próximo - e à capacidade de ajudar. (...) Com origem no termo em grego empatheia, que significava "paixão", a empatia pressupõe comunicação afetiva com outra pessoa (...). (In: https://www.significados.com.br/empatia/)

Responsabilidade Social. É quando as empresas decidem, voluntariamente, contribuir para uma sociedade mais justa e para um ambiente mais limpo. O conceito de responsabilidade social pode ser compreendido em dois níveis: o nível interno relaciona-se com os trabalhadores e, a todas as partes afetadas pela empresa e que, podem influenciar no alcance de seus resultados. O nível externo são as consequências das ações de uma organização sobre o meio ambiente, os seus parceiros de negócio. (https://www.significados.com.br/responsabilidadesocial/)

Em que se baseiam as ações solidárias daqueles e outros empresários, diante da covid-19? Depois de ler as matérias, me perguntei sobre o fundamento delas, e não sei, sinceramente, se consigo responder. A Revista "Isto É - Dinheiro" 
(https://www.istoedinheiro.com.br/a-economia-da-solidariedade/)

chama de "A economia da solidariedade":

Em meio à retração provocada pela pandemia de Covid-19, surge uma corrente do bem [grifo meu] liderada por empresas conscientes de sua responsabilidade social [grifo meu]. Ela envolve desde doações até a criação de fundos emergenciais para socorrer setores afetados pela paralisia nos negócios. Superar a maior crise global desde a Segunda Guerra exige empatia [grifo $m e u$ ] — e isso pode originar um novo capitalismo, mais consciente. (ibidem)

Em um único parágrafo, a Revista citou as três possibilidades de resposta: solidariedade, responsabilidade social e empatia! A reportagem diz que "outro contágio" - além daquele do vírus - se espalhou pelo mundo e afetou muita gente, começando com conversas informais pelas redes sociais entre amigos e familiares: surgiu, assim, uma "pauta de generosidade" (ibidem). A união para ações de solidariedade em épocas de crise entrou na lista das mudanças que o sistema financeiro vai organizar após a pandemia da covid-19 - é o que afirmam os presidentes dos três maiores bancos privados do país, em uma live: Itaú-Unibanco, Bradesco e Santander (https://oglobo.globo.com/economia/crise-do-coronavirusvai-provocar-mudancas-profundas-no-sistema-financeiro-do-paisdizem-banqueiros-24379733). A lista inclui: uso mais efetivo da tecnologia (vão adicionar, em um ano, mudanças que estavam previstas para cinco anos) e maior utilização do home office (a eficácia deste tipo de trabalho foi confirmada durante a pandemia). Com relação à "ação conjunta solidária", eles alegaram que a opinião da população com relação à instituição financeira está mudando: na crise de 2008 (que foi econômica e, não, de saúde), os bancos foram vistos, pela população, como culpados, e, agora, estavam sendo vistos como parte da solução, ao ajudarem a população diretamente (com doações) e indiretamente (ajudando as empresas a não demitirem funcionários). Por sua vez, a vice-presidente de Recursos Humanos do Banco Santander - Vanessa Lobato - assim se manifestou:

O que eu quero dizer é que, diante de um desafio tão grande, eu acho que se abre mão de burocracia, se abre mão de competição em prol de uma solução única. A colaboração, para mim, é um valor que está ficando evidente nessa crise. Eu acho que deveria ficar para sempre. (https://g1.globo.com/jornal- 
nacional/noticia/2020/04/14/solidariedade-sa-conhecaacoes-solidarias-de-empresas-e-empresarios-durante-apandemia.ghtml)

\section{Uma abordagem cristo-lógica}

Mas você deve estar se perguntando: por que revelar as marcas das empresas e suas boas ações? Elas não estarão querendo angariar mais lucros para seus negócios? Não seria por pura publicidade? É bem verdade que Jesus Cristo disse umas coisas muito interessantes, transcritas nos registros do evangelista São Mateus, no capítulo 6:

1."Guardai-vos de fazer vossas boas obras diante dos homens, para serdes vistos por eles. Do contrário, não tereis recompensa junto de vosso Pai que está no céu. 2.Quando, pois, dás esmola, não toques a trombeta diante de ti, como fazem os hipócritas nas sinagogas e nas ruas, para serem louvados pelos homens. Em verdade eu vos digo: já receberam sua recompensa. 3.Quando deres esmola, que tua mão esquerda não saiba o que fez a direita. 4.Assim, a tua esmola se fará em segredo; e teu Pai, que vê o escondido, irá recompensar-te.

(...) 19. "Não ajunteis para vós tesouros na terra, onde a ferrugem e as traças corroem, onde os ladrões furtam e roubam. 20.Ajuntai para vós tesouros no céu, onde não os consomem nem as traças nem a ferrugem, e os ladrões não furtam nem roubam. 21.Porque onde está o teu tesouro, lá também está teu coração.

(...) 24. "Ninguém pode servir a dois senhores, porque ou odiará a um e amará o outro, ou se dedicará a um e desprezará o outro. Não podeis servir a Deus e à riqueza. (...)

Já ouvi esses argumentos de muitos alunos também, em sala de aula: o que estaria "por trás" de muita ação de responsabilidade social nada mais seria que a pura intenção de publicidade e, portanto, maior lucro para suas contas bancárias! Mas é bem verdade que este, a meu ver, já é um "degrau" na escalada da ética na sociedade: é um bem feito - independentemente da intenção. Sejamos sinceros: não são muito frequentes os momentos em que nós fazemos o bem simplesmente por amor ao bem, ou ao próximo! Como dissociar um interesse pessoal de uma ação do bem - mesmo que seja um interesse afetivo?! Muita coisa que Jesus propõe e exemplifica ainda estamos longe de vivenciar! O apóstolo Mateus 
continua a nos mostrar o quanto Jesus nos desconcerta, no capítulo 21 de seu Evangelho:

(...) 28. "Que vos parece? Um homem tinha dois filhos. Dirigindo-se ao primeiro, disse-lhe: 'Meu filho, vai trabalhar hoje na vinha'. 29. Respondeu ele: 'Não quero'. Mas, em seguida, tocado de arrependimento, foi. 30. Dirigindo-se depois ao outro, disse-lhe a mesma coisa. O filho respondeu: 'Sim, pai!'. Mas não foi. 31. Qual dos dois fez a vontade do pai? 'O primeiro' - responderam-lhe. E Jesus disse-lhes: 'Em verdade vos digo: os publicanos e as meretrizes vos precedem no Reino de Deus!"

Muitos duros ensinamentos tiramos desta parábola. No primeiro grupo - o "primeiro filho" - estão as pessoas que, aparentemente, não são "boas", nem "éticas", possuem posturas questionáveis por não "obedecerem" àquilo que se espera delas; mas, arrependidas, fazem o que devem. No segundo grupo - o "segundo filho" -, estão as pessoas que, aparentemente, são "boas", "éticas", porque "obedecem", ou seja, não contradizem os valores que a ética propõe; entretanto, não praticam, não dão testemunho ético! Então, na minha modesta conclusão, parece que há mais peso ético naqueles que agem, que cumprem os valores éticos, e, não tanto, naqueles que discursam, "concordam", mas não praticam o bem. O segundo ensinamento que eu, humildemente, partilho com você, querido leitor, é referente ao arrependimento: sempre é tempo de acertar o passo, achar o caminho do bem, fazer com que o bem frutifique, dar bons exemplos - enfim, amar o próximo! Quem julgará?

O terceiro ensinamento que tiro para minha vida dos registros de São Mateus é referente ao combate ao preconceito: pecadores e meretrizes foram colocados acima daqueles que falam, mas não praticam! Claro que não quaisquer pecadores ou quaisquer meretrizes, mas aqueles e aquelas que se arrependem e praticam o bem. Convenhamos que os empresários já nos deram, sim, muitos motivos para desconfiança - quantas vezes não maldizemos o "sistema", o "mercado", e afins! Entretanto, devemos evitar, também, o preconceito - que, aliás, é sempre, um pré conceito: isto é, julgamos primeiro e buscamos as causas depois! De qualquer forma, o bem ao próximo deve ser sempre a meta dos que dizem seguir os exemplos e os ensinamentos de Jesus - na vida pessoal e na vida profissional. Quer uma humilde sugestão? Sigamos os bons exemplos e julguemos depois! Afinal, é o mesmo Jesus, o Cristo, que 
também nos ensina, através de nosso querido Mateus, no capítulo 6 de seu Evangelho:

28. (...) Considerai como crescem os lírios do campo; não trabalham nem fiam. 29. Entretanto, eu vos digo que o próprio Salomão no auge de sua glória não se vestiu como um deles. 30. Se Deus veste assim a erva dos campos, que hoje cresce e amanhã será lançada ao fogo, quanto mais a vós, homens de pouca fé? 31.Não vos aflijais, nem digais: Que comeremos? Que beberemos? Com que nos vestiremos?

(...) 33.Buscai em primeiro lugar o Reino de Deus e a sua justiça e todas estas coisas vos serão dadas em acréscimo.

Webliografia:

"A economia da solidariedade". In: Revista Isto É - Dinheiro. Edição № 1169 30.04. Acessada em: https://www. istoedinheiro.com.br/edicao/1169/.

"Abrace essa causa e faça a diferença na vida de muitas pessoas". In: Banco BV. In: https://bancobv.abraceumacausa.com.br/?utm_source=adwords\&utm _medium=texto\&utm_content=abraceummacausa_texto_ajuda_awa reness_adwaw002\&utm_campaign=brand db_awareness\&utm_term $=20020202 \&$ gclid=EAlalQobChMI5N779L CG6QIVjgyRCh0bOAesEAAYASAAEglk9vD_BwE.

"Atitude 3D voluntariado". In: Instagram. In: https://www.instagram.com/atitude3dvoluntario/ .

"Coronavírus: Rede D'Or do R\$ $110 \mathrm{mi}$ para ajudar hospitais públicos". In: ( $\mathrm{S} \quad \mathrm{U} \mathrm{N} \quad \mathrm{O}) . \quad$ In: https://www.sunoresearch.com.br/noticias/coronavirus-rede-d-or-doa110-mi-hospitais-publicos/

"Crise do coronavirus vai causar mudanças profundas no sistema financeiro do país, dizem banqueiros". In: O Globo. In: https://oglobo.globo.com/economia/crise-do-coronavirus-vaiprovocar-mudancas-profundas-no-sistema-financeiro-do-pais-dizembanqueiros-24379733.

"Empatia".

In:

Significados.

In:

https://www.significados.com.br/empatia/.

"Para você ficar em casa". In: Itaú. In: https://www.itau.com.br/coronavirus/.

SAKAMOTO, Leonardo. "Coronavirus não prefere pobre ou rico. Mas governos e suas políticas, sim". In: UOL. In: https://noticias.uol.com.br/colunas/leonardo- 
sakamoto/2020/03/15/coronavirus-nao-prefere-pobre-ou-rico-masgovernos-e-suas-politicas-sim.htm. Publicado em 15/03/2020.

"Significado de Responsabilidade Social". In: Significados. In: https://www.significados.com.br/responsabilidade-social/ .

"Solidariedade". In: Diocio. Dicionário online de Português. In: https://www.dicio.com.br/solidariedade/.

"Solidariedade S/A: conheça ações solidárias de empresas e empresários durante a pandemia". In: G1. Jornal Nacional. In: https://g1.globo.com/jornal-nacional/noticia/2020/04/14/solidariedadesa-conheca-acoes-solidarias-de-empresas-e-empresarios-durante-apandemia.ghtml .

"Todos pela Saúde". In: Itaú. In: https://www.itau.com.br/coronavirus/doacoes/.

"Vida em casa". In: Santander: Superamos juntos. In: https://br.superamosjuntos.com/vida-em-casa/. 